\title{
Altitude Stress During Participation of Medical Congress
}

\author{
Soon Bae Kim, MD', Jong Sung Kim, MD², Sang Jun Kim, MD, \\ Su Hee Cho, MD³, Dae Chul Suh, MD
}

Medical congresses often held in highlands. We reviewed several medical issues associated with altitude stress especially while physicians have participated medical congress held in high altitude. Altitude stress, also known as an acute mountain sickness (AMS), is caused by acute exposure to low oxygen level at high altitude which is defined as elevations at or above 1,200 $\mathrm{m}$ and AMS commonly occurs above 2,500 m. Altitude stress with various symptoms including insomnia can also be experienced in airplane. AMS and drunken state share many common features in symptoms, neurologic manifestations and even show multiple microbleeds in corpus callosum and white matter on MRI. Children are more susceptible to altitude stress than adults. Gradual ascent is the best method for the prevention of altitude stress. Adequate nutrition (mainly carbohydrates) and hydration are recommended. Consumption of alcohol can exacerbate the altitude-induced impairments in judgment and the visual senses and promote psychomotor dysfunction. For prevention or treatment of altitude stress, acetazolamide, phosphodiesterase inhibitors, dexamethasone and erythropoietin are helpful. Altitude stress can be experienced relatively often during participation of medical congress. It is necessary to remind the harmful effect of AMS because it can cause serious permanent organ damage even though the symptoms are negligible in most cases.

Key Words : Altitude stress; Acute Mountain Sickness; Airplane, Alcohol

Altitude stress or high-altitude illness is the collective term for acute mountain sickness (AMS), high-altitude cerebral edema, and high-altitude pulmonary oedema

\footnotetext{
Division of Nephrology, Department of Internal Medicine, ${ }^{2}$ Department of Neurology, ${ }^{3}$ Department of Radiology, College of Medicine, University of Ulsan, Asan Medical Center, Seoul, Korea Received August 4, 2016; accepted after revision August 17, 2016. Correspondence to: Dae Chul Suh, MD, Department of Radiology, College of Medicine, University of Ulsan, Asan Medical Center, 88, Olympic-ro 43-gil, Songpa-gu, Seoul 05505, Korea.

Tel. 82.2.3010.4366 Fax. 82.2.476.0090

E-mail: dcsuh@amc.seoul.kr

This is an Open Access article distributed under the terms of the Creative Commons Attribution Non-Commercial License (http://creativecommons.org/licenses/by-nc/3.0) which permits unrestricted non-commercial use, distribution, and reproduction in any medium, provided the original work is properly cited.
}

[1]. Because such illness may not be transient and even leaves a permanent damage to the brain, it would be necessary to know whether the meeting place locates at an intermediate (moderate) altitude (1300-2400 m) or at higher altitude where it usually requires acclimatization.

There are several congresses held in the highlands, that is, the areas which located in the high altitude. One of the authors already reported an article related with medical problems while participating the ABC-WIN seminar held in Val D'Isere every year [2]. The altitude of Val D'Isere, where for the congress has been held [2], is $1,850 \mathrm{~m}$. There are many famous areas in high altitude to visit on the way to Val D'Isere or other places nearby because it is located in the Alps. Aiguille du Midi in France, viewpoint for Mont Blanc, near Val 
D'Isere, is 3,842 $\mathrm{m}$ high. Jungfraujoch station in Swiss, also preferred place to visit, is $3,454 \mathrm{~m}$ high.

The most famous area in the medical field seems to be the Keystone Symposia, which are held every week from January to June, in several places at the same time, including neurological diseases as subjects, mainly in ski resorts including Keystone in Colorado. Base of the Keystone resort is 2,830 $\mathrm{m}$ high, the summit 3,782 m, and Pikes Peak 4,302m.

Besides congress visits, there are many highlands which can be freely accessible by car, train or cable car. For example, the world highest driveway is the Khardung La $(5,602 \mathrm{~m})$ located in the Ladakh region of the Indian state of Jammu and Kashmir. The highest railway station is the one in Tanggula $(5,072 \mathrm{~m})$ of Amdo County, Tibet Autonomous Region, China, near the border with the Tanggula Town, Qinghai. The highest cable car station is 4,508m high in Jade Dragon Snow Mountain, China.

Therefore, high altitude stress can be experienced in such areas while visiting those highland areas especially in case there is no caution to prevent it. Physicians who attend medical congress in highlands should be familiar with the symptoms of high-altitude illness and be encouraged not to ascend further if they have these symptoms. It is also helpful to have a flexible travel itinerary so that additional rest days can be incorporated if required. We reviewed two most common areas in high altitude; the Rocky Mountains in Colorado and the Alps in Europe where many medical congresses have been held and presented clinical features of altitude stress. We also emphasized a clinical condition of altitude stress which left organic sequels in the brain and discuss some management and preventive measures during participation of medical congress.

\section{Altitude}

Altitude is the vertical height above sea level of a land mass (for example, Mount Everest) or object (for example, aircraft). With increasing altitude, a decrease in the atmospheric barometric pressure causes a proportional decrease in the partial pressure of oxygen. Ultimately, with increasing altitude the oxygen partial pressure falls to a level at which there are measurable changes in physiological responses, physical and cognitive performance, and the emergence of altitude stress. Based on these measurements, functional definitions of altitude stress have been developed. In US army technical bulletin, altitude in "altitude stress" is defined as at or above 1,200 m (3,937 ft). At and above this elevation, the decreased availability of oxygen (that is, hypoxia) in the atmospheric air causes functional impairments and altitude stress. At this elevation, air pressure is $651 \mathrm{mmHg}(85.7 \%$ of sea level) and decrease of oxygen saturation is minimal. "Moderate" altitude extends from 1,200 to 2,400 m and "High" altitude extends from 2,400 to 4,000 m [3]. The Lake Louise Consensus Group defined "acute mountain sickness (AMS)" as the presence of headache in an unacclimatized person who has recently arrived at an altitude above $2,500 \mathrm{~m}$ plus the presence of one or more of the following: gastrointestinal symptoms (anorexia, nausea, or vomiting), insomnia, dizziness,

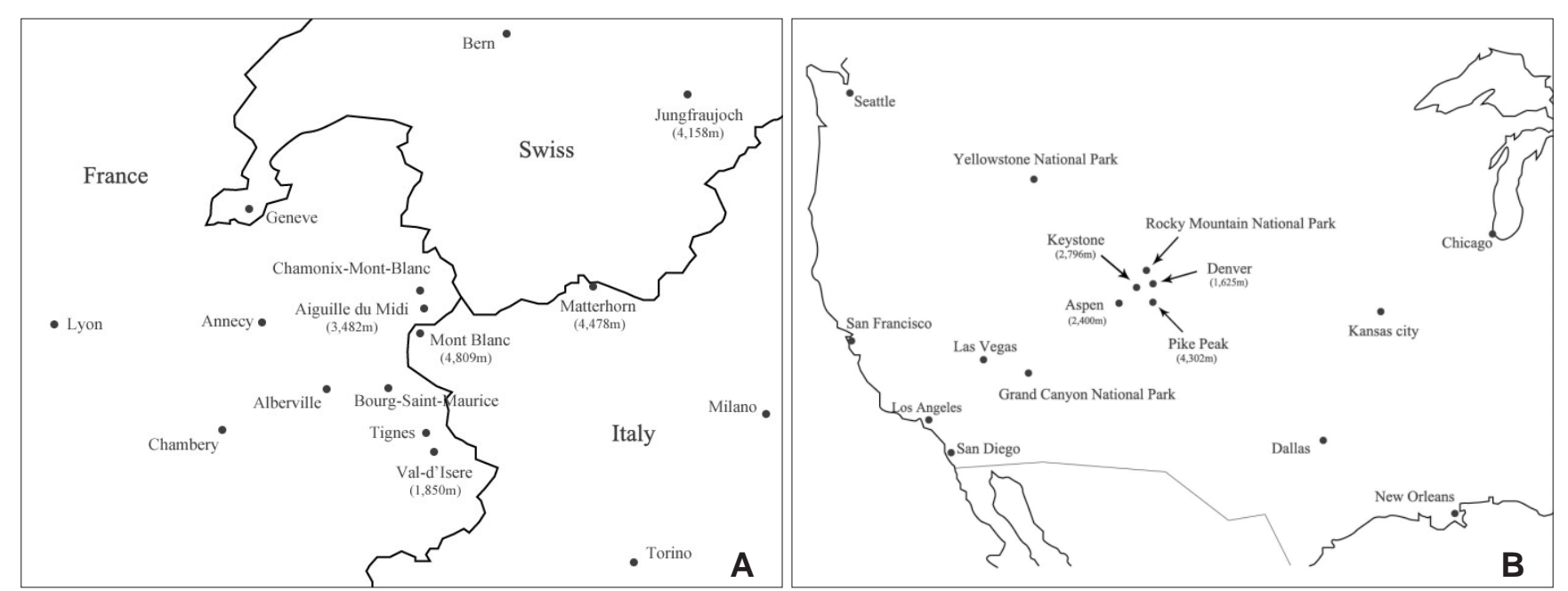

Fig. 1. Two representative medical meeting places in high altitude (A) the Alps in Europe (B) the Rocky Mountains in the North America. Parentheses indicate height in meter. 


\section{Altitude Stress During Participation of Medical Congress}

and lassitude or fatigue [4]. Therefore, altitude stress is more comprehensive term than AMS.

\section{Altitude acclimatization}

Gradual ascent is the best method for the prevention of altitude stress. US army recommended that unacclimatized soldiers should not ascend above $2,400 \mathrm{~m}$ and ascend not greater than $600 \mathrm{~m}$ per day between $2,400 \mathrm{~m}$ and $4,000 \mathrm{~m}$. Above $4,000 \mathrm{~m}$, graded ascent profiles should not exceed $300 \mathrm{~m}$ over 2 days and should include a non-ascent day every second or third day [3]. Cable car from Chamonix (1,035 m) to Aiguille du Midi (3,842 $\mathrm{m})$ ascends in about 40 minutes and train from Interlaken (568 $\mathrm{m})$ to Jungfraujoch station $(3,454$ $\mathrm{m})$ goes in 2 hours 17 minutes (Fig. 1A). A night spent at moderate altitude (1300-2400 $\mathrm{m}$ ) before ascent to high altitude will also aid acclimatization. For example, peoples who are resident at sea level will benefit from a night spent in Denver $(1625 \mathrm{~m})$ before joining a meeting in Aspen (base altitude 2400 m) (Fig. 1B) [1].

When one of the authors (SB Kim) visited Aiguille du Midi with his two children (11 and 8 years old), both children complained of headache in about 15 minutes and then collapsed in the observatory platform. They became well immediately after coming back to Chamonix downtown. This experience reveals that children are more susceptible to altitude stress [5].

Recently, a 52-year-old Korean lady with severe AMS ascended Tibet-side Everest base camp (5,200 m) by car in 5 days after departure from Seoul (sea level). Her average elevation speed was greater than 1,000 $\mathrm{m} /$ day. She was admitted to our institute with continuing headache and dizziness for 1 month after coming back from tour. Her MRI showed numerous microbleeds in the corpus callosum and both cerebral subcor- tical deep white matter on gradient recalled echo/susceptibility weighted imaging (Fig. 2).

\section{Airplane}

The first place where travellers experience altitude stress is airplane. A commonly encountered but generally unrecognized exposure to moderate altitude occurs during commercial flight. Although the cabins of commercial aircraft are pressurized to protect occupants from the very low barometric pressures at flight altitudes, sea-level pressure $(760 \mathrm{~mm} \mathrm{Hg})$ is not maintained. Instead, aircraft are designed to maintain cabin pressure at a level not lower than $565 \mathrm{~mm} \mathrm{Hg}$ (equivalent to an altitude of $8000 \mathrm{ft}[2,438 \mathrm{~m}], 75 \%$ of sea-level) when the airplane is at its maximum operating altitude [6]. Using pulse oximetry, the arterial oxygen saturation of 42 airline crew members was continuously monitored on 22 regularly scheduled commercial flights. Mean nadir arterial oxygen saturation fell from $97.0 \%$ preflight to $88.6 \%$ at cruising altitudes. Pulse oximetry results revealed large variations between individuals. Individual nadir saturations ranged from $93 \%$ to $80 \%$. Of the crew, $52.5 \%$ developed a $\mathrm{SaO} 2$ of less than $90 \%$ [6]. Mean measured fraction of inspired oxygen(FIO2\%) was $16.2 \%$ at 3 hours (cabin altitude equivalents 2,204 m) and $15.9 \%$ at 7 hours of flight (cabin altitude equivalents $2,087 \mathrm{~m}$ ) [7].

\section{Age/Gender}

Persons over 50 years of age are somewhat less susceptible to AMS than younger persons because of the decrease in brain size that occurs with increasing age [1, 8]. Preliminary data from neuroimaging measurements support the hypothesis that a tight brain is associated

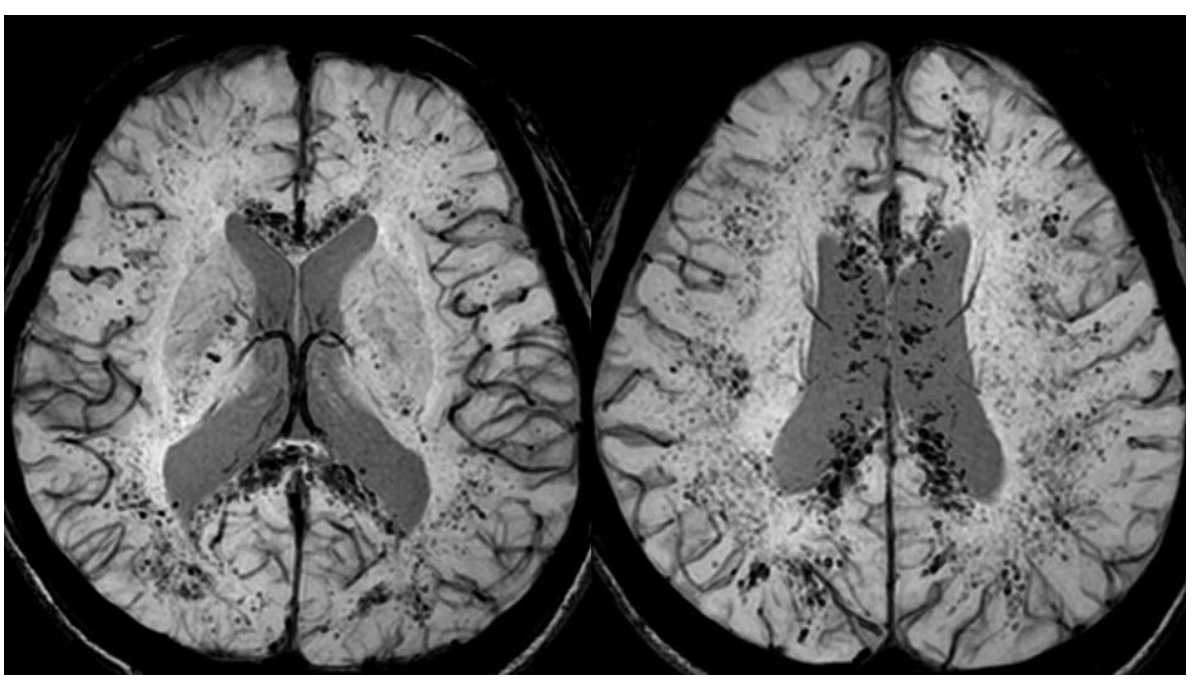

Fig. 2. A 52-year-old female shows numerous microbleeds in the corpus callosum and both cerebral subcortical deep white matter on susceptibility weighted imaging. Those MRI findings were regarded a sequel after acute mountain sickness 
with severity of AMS [8]. Children are more susceptible to altitude stress [5]. A higher incidence of AMS was observed in children (100\%) in Putre, Chile $(3,500$ $\mathrm{m})$ than in teenagers $(50 \%)$ and adults $(27 \%)$. Therefore, one should keep an eye on children in highlands or airplane. Most studies reveal no gender difference in AMS incidence [9].

\section{Insomnia}

Insomnia is one of five symptoms of AMS, which is accompanied by a report of compromised daytime function: Fatigue or malaise, poor attention or concentration, social or vocational/educational dysfunction, daytime sleepiness, reduced motivation or energy, increased errors or accidents, behavioral problems such as hyperactivity, impulsivity or aggression and ongoing worry about sleep. These changes can aggravate AMS as a vicious cycle. Acetazolamide (125 mg before bedtime) is useful because this agent decreases hypoxemic episodes and alleviates sleeping disruptions caused by excessive periodic breathing [9]. Because of the risk of respiratory depression, sedative hypnotic agents should be avoided in those with AMS unless they are combined with acetazolamide. Zolpidem (up to $10 \mathrm{mg}$ ) an hour before bedtime does not depress ventilation at high altitudes and may therefore be a safe treatment for insomnia in persons with AMS [3, 8]. It should be avoided in children, those who are breastfeeding, the elderly, and those with hepatic disease, major depression, pulmonary disease, respiratory depression, and suicidal ideation [3].

\section{Alcohol}

Consumption of alcohol can exacerbate the altitudeinduced impairments in judgment and the visual senses and promote psychomotor dysfunction [3]. Alcohol also depresses respiration, especially during sleep, causes hypoglycemia, and induces an undesirable diuresis [3]. Many surveys cited alcohol as the major cause of "air rage" [10]. Disruptive passenger behavior can range from noncompliance with safety instructions to the physical assault of airline staff. Alcohol consumption was more likely on longer flights, when traveling with friends, and anticipating the First or Business Class seating [10]. Passengers in an airplane became intoxicated approximately 3 times faster [2].

AMS and drunken state share many common features. Five symptom scores of AMS (headache, gastrointestinal symptoms, insomnia, dizziness, and lassitude or fatigue) are also symptoms of drunken state. Confusion, mood and behavioral changes, memory difficulty, diplopia, and ataxia ("drunken stagger") are common neurological signs of both AMS and drunken state.

Both AMS and drunken state affect the corpus callosum. The MRI findings of increased signal in the white matter and particularly in the splenium of the corpus callosum are confirmatory of high-altitude cerebral edema [9], like our case. Many infants prenatally exposed to high levels of alcohol show one particular anomaly of the corpus callosum [11] and even moderate amounts of alcohol may be detrimental to the corpus callosum and white matter integrity in older adults [12].

\section{Gastrointestinal issues and Nutrition}

Gastrointestinal symptoms (anorexia, nausea, or vomiting) and lassitude or fatigue are two of five symptoms of AMS. Anorectic and tired tourists may skip meals, but this practice will make them more susceptible to high altitude injury and further fatigue. Eating small meals five to seven times a day and higher caloric intake meals to compensate for the extra calories burned in the altitude environment are recommended [3]. Carbohydrates are the best fuel source in a low $\mathrm{O} 2$ environment, because hypoxic exposure causes an increase in glucose uptake and carbohydrates provide the most energy adenosine triphosphate (ATP) per molecule of O2 transported through the mitochondrial electron transport chain [3].

Providing time for meals will ensure proper hydration as well as energy intake because fluid intake is the greatest at mealtime. Hydration state can be monitored by noting the color and volume of urine. Dark yellow urine and infrequent urination indicate fluid intake must increase. Soups are an excellent source of nutrition and hydration [3].

Because of decreased atmospheric pressure and consequent intestinal gas expansion at high altitudes, many sojourners experience abdominal bloating and distension as well as excessive flatus expulsion. In the absence of diarrhea, these phenomena are normal. Accompanying diarrhea, however, may indicate the involvement of bacteria or Giardia parasites, which are common at many high-altitude locations in the developing world. Prompt treatment with fluids and empirical antibiotics may be required [9].

\section{Prevention and Treatment}

Gradual ascent is the best method for the prevention of altitude stress. If you have to go highlands rapidly, acetazolamide (125-250 mg twice a day), is the drug of 
choice for AMS prevention. Paresthesia and a tingling sensation are common side effects of acetazolamide. Dexamethasone (Diamox ${ }^{\circledR}, 8 \mathrm{mg} / \mathrm{d}$ in divided doses) is also effective [9].

Phosphodiesterase inhibitors, sildenafil (Viagra ${ }^{\circledR}, 50$ mg every $8 \mathrm{hrs}$ ) and tadalafil (Cialis ${ }^{\circledR}, 10 \mathrm{mg}$ twice) are used for the prevention of high-altitude pulmonary oedema because of the pulmonary vasodilator effects associated with these medications [13]. Recently, we reported that increasing hemoglobin before ascent by prophylactic erythropoietin injections prevents AMS [14]. Erythropoietin has nonerythropoietic properties that protect the brain, spinal cord and retina from ischemic and other types of injury, independently of its effect on hemoglobin $[15,16]$.

\section{CONCLUSIONS}

There are two most common areas in high altitude; the Rocky Mountains in Colorado and the Alps in Europe where many medical congresses have been held. Physicians who attend such a meeting place in high altitude need to understand clinical features of altitude stress. Arterial oxygen saturation fell due to low barometric pressure at cruising altitudes in the airplane. AMS and drunken state share many common features in symptoms, neurologic manifestations and abnormality in the corpus callosum and the white matter on MRI. Consumption of alcohol can exacerbate the altitude-induced impairments in judgment and the visual senses and promote psychomotor dysfunction. Insomnia caused by altitude change can aggravate altitude stress. Zolpidem can be a safe medication because it does not depress ventilation at high altitudes. Children are more susceptible to altitude stress than adults. Adequate nutrition (mainly carbohydrates) and hydration are important. Gradual ascent is the best method for the prevention of altitude stress. For prevention or treatment of altitude stress, acetazolamide, phosphodiesterase inhibitors, dexamethasone and erythropoietin are helpful.

\section{References}

1. Basnyat B, Murdoch DR. High-altitude illness. Lancet 2003;361:1967-1974
2. Park D, Kim M, Lee GY, Yang KH, Park HS, Suh DC. Medical Problems during Participation of Medical Congress - A Long Trip to Val D'Isere from Korea. Neurointervention 2016;11:1-4

3. U.S. Army Research Institute of Environmental Medicine. Altitude accli-matization and illness management: Technical Bulletin Medical 505, 1st ed. Washington DC: U.S. Department of the Army, 2010;1-119

4. Roach RC, B Bearch institute of environmental meake louise consensus committee. The lake louise acute mountain sickness scoring system. In: Sutton jr, houston cs, coates g, editors. Hypoxia and molecular medicine. Burlington: Queen city printers, 1993, 272-274

5. Moraga FA, Osorio JD, Vargas ME. Acute mountain sickness in tourists with children at Lake Chungara $(4400 \mathrm{~m})$ in northern Chile. Environ Med 2002;13:31-35

6. Cottrell JJ, Lebovitz BL, Fennell RG, Kohn GM. Inflight arterial saturation: continuous monitoring by pulse oximetry. Aviat Space Environ Med 1995;66:126-130

7. Lee AP, Yamamoto LG, Relles NL. Commercial airline travel decreases oxygen saturation in children. Pediatr Emerg Care 2002;18:78-80

8. Hackett PH, Roach RC. High-altitude illness. N Engl J Med 2001; 345:107-114

9. Basnyat B, Tabin G. Altitude illness. In: Kasper DL, Fauci AS, Hauser SL, Longo DL, Jameson JL, Loscalzo J. Harrison's Principles of Internal Medicine, 19th ed. New York: McGrawHill, 2015, 476e-1-e-6

10. Girasek DC, Olsen CH. Airline passengers' alcohol use and its safety implications. J Travel Med 2009;16:311-316

11. Bookstein FL, Connor PD, Huggins JE, Barr HM, Pimentel KD, Streissguth AP. Many infants prenatally exposed to high levels of alcohol show one particular anomaly of the corpus callosum. Alcohol Clin Exp Res 2007;31:868-879

12. Kapogiannis D, Kisser J, Davatzikos C, Ferrucci L, Metter J, Resnick SM. Alcohol consumption and premotor corpus callosum in older adults. Eur Neuropsychopharmacol 2012;22:704-710

13. Luks AM, McIntosh SE, Grissom CK, Auerbach PS, Rodway GW, Schoene RB, et al. Wilderness Medical Society consensus guidelines for the prevention and treatment of acute altitude illness. Environ Med 2010;21:146-155

14. Heo K, Kang JK, Choi CM, Lee MS, Noh KW, Kim SB. Prophylactic effect of erythropoietin injection to prevent acute mountain sickness: an open-label randomized controlled trial. $J$ Korean Med Sci 2014;29:416-422

15. Coleman T, Brines M. Science review: recombinant human erythropoietin in critical illness: a role beyond anemia? Crit Care 2004;8:337-341

16. Miskowiak K, Inkster B, O’Sullivan U, Selvaraj S, Goodwin GM, Harmer CJ. Differential effects of erythropoietin on neural and cognitive measures of executive function 3 and 7 days postadministration. Exp Brain Res 2008;184:313-321 